\title{
Níveis de treonina digestível em dietas para fêmeas suínas de alto potencial genético em lactação sob condições de alta temperatura ambiente ${ }^{*}$
}

\section{Charles Kiefer ${ }^{1}$, Aloízio Soares Ferreira ${ }^{2}$, Rita Flávia Miranda de Oliveira ${ }^{2}$, Juarez Lopes Donzele $^{2}$, Alfredo Sampaio Carrijo ${ }^{1}$, Francisco Carlos de Oliveira Silva ${ }^{3}$}

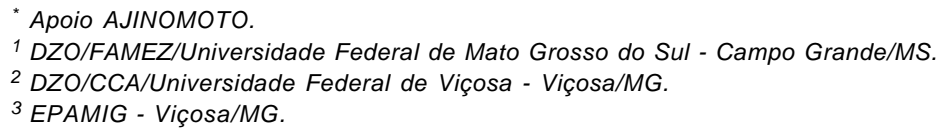

RESUMO - Foram utilizadas 52 fêmeas suínas em lactação distribuídas em delineamento experimental de blocos ao acaso, composto de quatro níveis de treonina digestível $(0,64 ; 0,67 ; 0,70$ e $0,73 \%)$ na dieta e 13 repetições, em que cada unidade experimental foi constituída por uma fêmea. A temperatura do ar no interior das salas foi de $29,7 \pm 2,5^{\circ} \mathrm{C}$. $\mathrm{Não}$ houve efeito dos níveis de treonina digestível na dieta sobre o peso das fêmeas ao desmame. As perdas total e percentual de peso das fêmeas durante a lactação reduziram de forma linear com o aumento dos níveis de treonina digestível na dieta. Os níveis de treonina digestível influenciaram a espessura de toucinho (ET) ao desmame e afetaram as variações total e percentual de espessura de toucinho. As composições de gordura e proteína corporal à desmama não foram influenciadas pelos níveis de treonina digestível na dieta. Verificou-se redução linear das mobilizações total e percentual de gordura corporal conforme aumentaram os níveis de treonina digestível na dieta. A mobilização de proteína corporal, a produção de leite e o intervalo desmama-estro não foram influenciados pelos níveis de treonina digestível da dieta. Os níveis de treonina digestível não afetaram os consumos de ração, de lisina e de energia digestível. Contudo, verificou-se aumento linear do consumo de treonina digestível conforme aumentou o nível deste aminoácido na dieta. Os níveis de treonina digestível não influenciaram a eficiência energética das fêmeas e o desempenho dos leitões e das leitegadas. Fêmeas suínas de alto potencial genético em lactação sobcondições de temperaturas ambientais elevadas exigem $0,73 \%$ de treonina digestível, correspondente ao consumo diário de $32,5 \mathrm{~g}$ e à relação treonina digestível:lisina digestível de $73 \%$.

Palavras-chave: aminoácidos, estresse por calor, exigência, lactação, leitões

\section{Digestible threonine levels of high-producing lactating sows maintained under high temperature environment conditions}

\begin{abstract}
Fifty and two lactating sows were allotted to a randomized complete blocks experimental design with four digestible threonine levels $(0.64 ; 0.67 ; 0.70$ and $0.73 \%)$ and 13 replications, and each experimental unit was consisted by a female. The temperature inside in the room was of $29.7 \pm 2.5^{\circ} \mathrm{C}$. There was no effect of digestible threonine levels in the diet on the weight of the sows at weaning. The total and percentage sow weight losses linearly reduced with the increase of digestible threonine level in the diet during the lactation period. Digestible threonine level in the diets influenced fat thickness (FT) at weaning, and affected the total and percentage variation of FT. The compositions of fat and corporal protein at weaning were not influenced by digestible threonine levels in the diet. A linear reduction for total and percentage of corporal fat mobilizations was observed as digestible threonine levels increased in the diet. The mobilization of corporal protein, milk production and the interval weaning time-estrus were not influenced by digestible threonine levels in the diet. Digestible threonine leveld in the diet had no effect on intake of diet, of lysine and of digestible energy. However, a linear increase was observed for the intake of digestible threonine as the levels of it increased in the diet. Digestible threonine levels in the diet had not influenced the energy efficiency of the females, the performance of the piglets and the litters. High-producing lactating sows under high temperature environmental conditions require $0.73 \%$ of digestible threonine, corresponding to a daily intake of $32.5 \mathrm{~g}$ and the digestible threonine:digestible lysine ratio of $73 \%$.
\end{abstract}

Key Words: amino acids, heat stress, lactation, litter, piglets, requirement

\section{Introdução}

O grande avanço no desempenho produtivo da suinocultura verificado nos últimos anos se deve, em grande parte, à intensa seleção aplicada em genótipos de linhas maternas. A partir da seleção, têm-se obtido matrizes cada vez mais prolíferas (aproximadamente $40 \%$ superior no número de leitões nascidos por parto em relação às ances- 
trais), de rápido crescimento corporal, com carcaça de baixa porcentagem de gordura e com alta capacidade de produção de leite.

Apesar de mais produtivas, as matrizes contemporâneas apresentam menor apetite e menor capacidade de ingestão alimentar (Sauber et al., 1994), o que reflete em aumento de mobilização de tecidos corporais durante a lactação, uma vez que o consumo de nutrientes não supre as exigências para adequada produção de leite. No entanto, a elevada perda de peso corporal durante a lactação tem prejudicado a eficiência reprodutiva das fêmeas, principalmente o retorno ao estro e o tamanho da leitegada subseqüente (Boyd et al., 2000).

Vários fatores podem afetar o consumo de alimento por matrizes contemporâneas na fase de lactação, entre eles, a temperatura ambiental. Em ambientes de altas temperaturas, o consumo voluntário de alimento e a produção de leite pelas fêmeas são reduzidos como mecanismo para evitar o aumento da temperatura corporal (Quiniou \& Noblet, 1999; Renaudeau et al., 2001).

A redução da produção de leite em condições de altas temperaturas pode ser explicada pela redução do consumo de alimento, que está associada à redução da disponibilidade de nutrientes para síntese do leite. Contudo, resultados de pesquisas realizadas por Bragança et al. (1998) sugeriram um efeito direto da temperatura de ambiente sobre a produção de leite. Segundo esses autores, a capacidade da fêmea lactante em mobilizar e redistribuir os nutrientes dos tecidos de reserva para a glândula mamária é prejudicada sob condições de temperaturas elevadas, seja pela alteração das funções endócrinas seja pelo redirecionamento do fluxo sanguíneo para a periferia corporal para aumento da perda de calor corporal. Renaudeau et al. (2003) também concluíram que a ineficiência aparente das glândulas mamárias de fêmeas suínas em lactação mantidas em ambientes de altas temperaturas pode estar relacionada ao aumento da proporção do fluxo sanguíneo destinado à irrigação dos capilares da pele visando à dissipação do calor corporal. Assim, os nutrientes dietéticos e os mobilizados a partir das reservas corporais são, muitas vezes, insuficientes para atender à produção de leite e manter adequada condição corporal em condições de temperaturas ambientais elevadas.

Além disso, o aumento da capacidade produtiva das matrizes tem alterado significativamente a exigência nutricional (Cooper et al., 2001). Pesquisas recentes têm demonstrado que a ordem de limitação aminoacídica varia de acordo com a mobilização de tecidos e que, entre os aminoácidos, a treonina pode ser o primeiro limitante em dietas para fêmeas suínas na fase de lactação quando ocorre alta mobilização de tecidos corporais (Kim et al., 2001). Entretanto, existem poucas informações sobre a exigência de treonina para matrizes lactantes mantidas em ambiente de altas temperaturas ambientais. Neste contexto, propôs-se realizar este estudo com o objetivo de avaliar níveis de treonina digestível em dietas para fêmeas suínas de alto potencial genético em lactação em ambientes de altas temperaturas.

\section{Material e Métodos}

O experimento foi conduzido na Suinocultura Rancho Alegre, localizada no município de Campo Grande, MS, durante os meses de fevereiro e março de 2006. Foram utilizadas 52 fêmeas de alto potencial genético do primeiro ao oitavo parto, com ordem de parto de 4,62 $\pm 2,40$ e peso inicial de 258,18 $\pm 35,65 \mathrm{~kg}$, distribuídas em delineamento experimental de blocos ao acaso, composto por quatro níveis de treonina digestível $(0,64 ; 0,67 ; 0,70$ e $0,73 \%$, correspondentes, respectivamente, às relações de 0,64 ; 0,$67 ; 0,70$ e $0,73 \%$ com a lisina digestível) e 13 repetições, em que cada unidade experimental foi composta de uma fêmea. Na formação dos blocos, foram considerados o peso corporal e a ordem de parto das fêmeas.

As dietas experimentais (Tabela 1) foram formuladas para atender às exigências em aminoácidos, com exceção da treonina. Além disso, exceto a treonina, cujos níveis e relações variaram, as relações dos demais aminoácidos com a lisina atenderam às relações mínimas preconizadas por Kim et al. (2001). Os diferentes níveis de treonina digestível foram obtidos pela inclusão de L-treonina em substituição ao amido.

Considerando o nível de $0,781 \%$ de treonina total analisado e o coeficiente de digestibilidade médio para a treonina de $82,9 \%$, conforme Rostagno et al. (2005), o nível de treonina digestível da dieta basal (Tabela 2) foi de $0,647 \%$ e, considerando a digestibilidade de $94,7 \%$ da L-treonina para suínos, segundo Rostagno et al. (2005), os níveis de treonina digestível das dietas experimentais foram de 0,647 ; 0,$677 ; 0,706$ e $0,737 \%$.

As dietas experimentais foram fornecidas às fêmeas após o parto até o desmame, efetuando-se o aumento gradativo do fornecimento, iniciando-se com a quantidade diária de 1,0 kg visando atingir consumo diário de 4,0 kg ao quarto dia após o parto. A partir do quarto dia e até o desmame, as dietas experimentais foram fornecidas à vontade às fêmeas, sendo distribuídas em até quatro refeições diárias. Durante todo o período experimental, as dietas 
Tabela 1 - Composições centesimal e nutricional das dietas experimentais ${ }^{1}$

Table 1 - Percentage and nutricional compositions of the experimental diets

\begin{tabular}{|c|c|c|c|c|}
\hline \multirow[t]{2}{*}{$\begin{array}{l}\text { Ingrediente } \\
\text { Ingredient }\end{array}$} & \multicolumn{4}{|c|}{$\begin{array}{c}\text { Nível de treonina digestível (\%) } \\
\text { Digestible threonine level }\end{array}$} \\
\hline & 0,64 & 0,67 & 0,70 & 0,73 \\
\hline Milho (Corn) & 49,510 & 49,510 & 49,510 & 49,510 \\
\hline Farelo de soja (45\% PB) (Soybean meal, $45 \%$ CP) & 31,247 & 31,247 & 31,247 & 31,247 \\
\hline Sorgo baixo tanino (Low tanine sorgum) & 10,780 & 10,780 & 10,780 & 10,780 \\
\hline Óleo de soja (Vegetable oil) & 4,024 & 4,024 & 4,024 & 4,024 \\
\hline Fosfato bicálcico (Dicalcium phosphate) & 1,916 & 1,916 & 1,916 & 1,916 \\
\hline Calcário (Limestone) & 1,299 & 1,299 & 1,299 & 1,299 \\
\hline Premix vitamínico-mineral ${ }^{1}$ (Mineral/vitamin mix) & 0,500 & 0,500 & 0,500 & 0,500 \\
\hline Sal (Salt) & 0,497 & 0,497 & 0,497 & 0,497 \\
\hline L-lisina $\mathrm{HCl}($ L-lysine $\mathrm{HCl})$ & 0,127 & 0,127 & 0,127 & 0,127 \\
\hline Amido (Starch) & 0,100 & 0,068 & 0,037 & 0,005 \\
\hline L-treonina (L-threonine) & 0,000 & 0,032 & 0,063 & 0,095 \\
\hline Relação treonina: lisina (Threonine:lysine ratio) & 64 & 67 & 70 & 73 \\
\hline $\mathrm{PB}(C P)(\%)$ & 19,498 & 19,498 & 19,498 & 19,498 \\
\hline $\mathrm{EM}(M E)(\mathrm{kcal} / \mathrm{kg})$ & 3.320 & 3.320 & 3.320 & 3.320 \\
\hline Lisina total $(\%)$ (Total lysine) & 1,143 & 1,143 & 1,143 & 1,143 \\
\hline Lisina digestível (\%) (Digestible lysine) & 1,000 & 1,000 & 1,000 & 1,000 \\
\hline Met + cist digestível $(\%)($ Digestible met + cist $)$ & 0,550 & 0,550 & 0,550 & 0,550 \\
\hline Treonina digestível (\%)(Digestible threonine) & 0,640 & 0,670 & 0,700 & 0,730 \\
\hline Triptofano digestível (\%)(Digestible thriptophan) & 0,210 & 0,210 & 0,210 & 0,210 \\
\hline Valina digestível (\%) (Digestible valyne) & 0,816 & 0,816 & 0,816 & 0,816 \\
\hline $\mathrm{Ca}(\%)$ & 1,100 & 1,100 & 1,100 & 1,100 \\
\hline P disponível (\%) (Available P) & 0,460 & 0,460 & 0,460 & 0,460 \\
\hline $\mathrm{Na}(\%)$ & 0,220 & 0,220 & 0,220 & 0,220 \\
\hline
\end{tabular}

1 Conteúdo/kg(Content/kg): Fe - $100 \mathrm{~g} ; \mathrm{Cu}-10 \mathrm{~g}$; Co - 0,2 g; Mn - 30 g; Zn - $100 \mathrm{~g} ; \mathrm{I}-1,0 \mathrm{~g} ; \mathrm{Se}-0,3 \mathrm{~g} ;$ vit. A - 6.000.000 Ul; vit. D -1.000 .000 UI; vit. E - 12.00 oUl; vit. $B_{1}-0,5 \mathrm{~g}$; vit. $B_{2}-2,6 \mathrm{~g}$; vit. $\mathrm{B}_{6}-0,7 \mathrm{~g}$; ácido pantotênico (pantothenic acid) - $10 \mathrm{~g}$; vit. $\mathrm{K}_{3}-1,5 \mathrm{~g}$; ácido nicotínico (nicotinic acid) - $22 \mathrm{~g}$; vit. B12 - 0,015 g; ácido fólico (folic acid) - 0,2 g; biotina (biotin) - 0,05 g; colina (choline) - $100 \mathrm{~g}$; excipiente q.s.p. (vehicle q.s.p.) - $1.000 \mathrm{~g}$.

Tabela 2 - Composição nutricional analisada da dieta basal

Table 2 - Analyzed nutritional composition of the basal diet

\begin{tabular}{|c|c|c|c|}
\hline $\begin{array}{l}\text { Nutriente } \\
\text { Nutrient }\end{array}$ & $\begin{array}{c}\text { Total }(\%)^{1} \\
\text { Total }\end{array}$ & $\begin{array}{c}\mathrm{CD}(\%)^{2} \\
C D\end{array}$ & $\begin{array}{c}\text { Digestível (\%) } \\
\text { Digestible }\end{array}$ \\
\hline Proteína bruta (Crude protein) & 21,09 & - & - \\
\hline Lisina (Lysine) & 1,178 & 88,0 & 1,040 \\
\hline Treonina (Threonine) & 0,781 & 82,9 & 0,647 \\
\hline Metionina + cistina (Methionine + cystine) & 0,636 & 89,9 & 0,571 \\
\hline Valina (Valine) & 0,942 & 86,9 & 0,818 \\
\hline Arginina (Arginine) & 1,330 & 92,6 & 1,231 \\
\hline Histidina (Histidine) & 0,570 & 90,3 & 0,515 \\
\hline Leucina (Leucine) & 1,759 & 90,4 & 1,590 \\
\hline Isoleucina (Isoleucine) & 0,854 & 88,0 & 0,751 \\
\hline Fenilalanina (Phenylalanine) & 1,030 & 89,4 & 0,921 \\
\hline
\end{tabular}

${ }^{1}$ Laboratório Ajinomoto; ${ }^{2}$ CD (Coeficiente de digestibilidade conforme Rostagno et al., 2005).

${ }^{1}$ Ajinomoto Laboratory; ${ }^{2} C D$ (Coefficient of digestibility in agreement Rostagno et al., 2005).

foram fornecidas úmidas, na proporção de 1:1 (ração:água), visando maximizar o consumo voluntário das fêmeas. As sobras de ração dos comedouros foram coletadas e pesadas após cada refeição para determinação do consumo diário de ração. Considerando que $50,0 \%$ das sobras foram compostas de água, os pesos das sobras foram divididos por dois. Durante a lactação, os leitões tiveram acesso à água por meio de bebedouros do tipo chupeta e, a partir do oitavo dia de idade, iniciou-se o fornecimento de dieta pré-inicial.
As fêmeas foram pesadas 24 horas após o parto e ao desmame, realizado no 21 o dia de lactação. As leitegadas também foram pesadas 24 horas após o nascimento e ao desmame.

Foi medida em aparelho de ultra-sonografia a espessura de toucinho no ponto $\mathrm{P}_{2}(6,5 \mathrm{~cm}$ da linha dorsal no nível da 10 a costela) 24 horas após o parto e ao desmame. Ao final do período de lactação, foi estimada a produção de leite das fêmeas, com base no ganho de peso do leitão no período, 
no tamanho da leitegada e na duração da lactação, de acordo com equação proposta por Ferreira et al. (1988), em que: produção de leite $(\mathrm{kg} /$ dia $)=[(4,27 \times$ ganho de peso do leitão no período, $\mathrm{kg}) \times \mathrm{n}^{\circ}$ leitões $] / \mathrm{n} \mathrm{o}$ dias de lactação.

O balanço de energia das matrizes durante a lactação foi estimado utilizando-se o modelo de equações para predição da exigência dos suínos (modelo lactacional) publicado pelo NRC (1998), em que o consumo diário de energia durante o período experimental é calculado pela multiplicação do conteúdo de energia da dieta pelo consumo diário. A exigência de energia para mantença foi calculada com base no peso corporal (PC) das fêmeas: energia de mantença $(\mathrm{MJ} E M /$ dia $)=0,44 \mathrm{MJ}$ de $\mathrm{EM} \times \mathrm{PC}^{0,75}$. O peso corporal utilizado para o cálculo foi a média entre os pesos inicial (24 horas após o parto) e final (desmama).

Para estimar a exigência de energia para produção de leite, foi calculada a quantidade de energia transferida da porca para a leitegada: energia para produção de leite (MJ energia bruta/dia $)=[(4,92 \times$ ganho médio da leitegada, $\mathrm{g} / \mathrm{dia})$ - $(90 \times$ número de leitões $)] \times 0,00419$. Assumindo-se que a eficiência de energia da dieta para produção de leite é de 0,72 e que a eficiência de energia mobilizada do tecido é de 0,88 , determinou-se o balanço de energia (BE) como: BE (MJ/dia) = consumo energia - (energia de mantença + energia para produção de leite).

A quantidade de gordura mobilizada durante a lactação foi estimada pelas quantidades de gordura corporal 24 horas após o parto e ao desmame a partir dasvariáveis peso corporal e espessura de toucinho, de acordocom a equação de regressão proposta por CVB (1994), em que: gordura $\operatorname{corporal}(\mathrm{kg})=-11,58+(0,1027 \times \mathrm{PC}, \mathrm{kg})+\left(1,904 \times \mathrm{ETP}^{2}, \mathrm{~mm}\right)$.

A quantidade de proteína mobilizada durante a lactação foi estimada pelas quantidades de proteína corporal 24 horas após o parto e ao desmame a partir do peso corporal e da espessura de toucinho, conforme equação de regressão citada por Clowes et al. (2003), em que: proteína corporal $(\mathrm{kg})=-2,3+\left[(0,19 \times \mathrm{PC}, \mathrm{kg})-\left(0,22 \times \mathrm{ET} \mathrm{P}_{2}, \mathrm{~mm}\right)\right]$.

Considerou-se que toda a gordura corporal mobilizada foi oriunda do tecido adiposo. A quantidade de perda de tecido adiposo e de proteína durante a lactação foi calculada considerando-se que o tecido adiposo contém $900 \mathrm{~g}$ de gordura/kg e o tecido protéico, $230 \mathrm{~g}$ de proteína/kg. Para estimar a quantidade de energia mobilizada da gordura e de proteína utilizada para a produção de leite, considerou-se conteúdo de energia de 39,4 MJ/kg para gordura e de energia de 23,5 MJ/kg para proteína (NRC, 1998).

A eficiência energética das fêmeas foi estimada em razão do consumo de ração e da produção de leitões. Esse método consiste em estimar a quantidade energética de peso corporal mobilizada pela fêmea durante a lactação, a quantidade de energia ingerida por meio do consumo de ração e a quantidade de energia gerada em razão da produção de leitões, determinando a relação entre essas variáveis. A quantidade de energia produzida por quilograma de carne de suíno em crescimento foi estimada em 16,49 mcal $\mathrm{EM} / \mathrm{kg}$ de proteína e $12,91 \mathrm{mcal} \mathrm{EM} / \mathrm{kg}$ de gordura e a quantidade de energia produzida por $\mathrm{kg}$ de peso perdido pela fêmea durante a lactação, em 10,52 mcal EM/kg (Whittemore \& Elsley, 1979).

A temperatura e a umidade relativa do ambiente foram registradas diariamente às 7,12 e $17 \mathrm{~h}$, durante todo o período experimental, por meio de um conjunto de termômetros de máxima e mínima, de bulbo seco e bulbo úmido e de globo negro instalados no centro da sala, à meiaaltura do corpo dos animais. Os valores registrados foram posteriormente convertidos no índice de temperatura de globo e umidade (ITGU), segundo Buffington et al. (1981), caracterizando o ambiente térmico em que os animais foram mantidos.

No período entre o desmame e a cobertura subseqüente, as fêmeas foram alojadas em gaiolas individuais e alimentadas com 2,0 kg de ração convencional de lactação, distribuídos em duas refeições diárias.

As fêmeas foram observadas diariamente para detecção do estro, levando-se o cachaço duas vezes ao dia às baias das fêmeas. Foram consideradas em estro as fêmeas que apresentaram reflexo de tolerância ao homemna presença do macho. As datas do desmame e de manifestação do estro foram consideradas no cálculo do intervalo desmama-estro. Uma vez diagnosticado o estro, as matrizes foram inseminadas artificialmente, com a primeira cobertura realizada 12 horas após a manifestação do estro.

Os dados obtidos foram submetidos a análises estatísticas utilizando-se o programa estatístico SAS (1996). As variáveis foram analisadas pela covariável consumo diário de ração e a estimativa da exigência de treonina digestível, determinada pelo modelo de regressão linear ou quadrática, segundo o melhor ajuste obtido para cada variável.

\section{Resultados e Discussão}

Durante o período experimental, a temperatura do ar das salas foi $29,7 \pm 2,5^{\circ} \mathrm{C}$, a umidade relativa foi $70,5 \pm 10,9 \%$ e a temperatura de globo negro foi $31,3 \pm 2,7^{\circ} \mathrm{C}$. A temperatura média do ar obtida neste estudo pode ser considerada de estresse por calor, por estar acima da faixa de temperaturas entre 15 e $20^{\circ} \mathrm{C}$ considerada ideal para esta categoria animal (Black et al., 1993; Bragança et al., 1998).

O ITGU calculado durante o período experimental foi de $80,9 \pm 2,8$. Segundo Turco et al. (1998), valores de ITGU 
superiores a 72 elevam a frequência respiratória e temperatura retal de matrizes suínas em lactação e evidenciam a ocorrência de desconforto e estresse térmico. Assim, o valor de ITGU de 80,9 observado neste estudo pode ser caracterizado como de ambiente de estresse por calor.

Não foi verificado efeito $(\mathrm{P}>0,10)$ dos níveis de treonina sobre os pesos das fêmeas ao desmame (Tabela 3). Verificou-se, no entanto, efeito sobre a variação dos pesos total $(\mathrm{P}<0,01)$ e percentual $(\mathrm{P}<0,05)$ das fêmeas durante a lactação; as perdas reduziram de forma linear com o aumento do nível de treonina digestível na dieta (Figura 1).

A espessura de toucinho ao desmame apresentou au mento linear $(\mathrm{P}<0,04)$ conforme aumentaram os níveis de treonina digestível da dieta: $\hat{\mathrm{Y}}=-4,0457+29,067 \mathrm{X}\left(\mathrm{r}^{2}=0,81\right)$.

Os níveis de treonina digestível influenciaram as variações total $(\mathrm{P}<0,05)$ e percentual $(\mathrm{P}<0,05)$ de espessura de toucinho das matrizes, que variaram de forma linear, reduzindo conforme aumentou o nível de treonina digestível da dieta (Figura 2).

Não foi constatada influência $(\mathrm{P}>0,10)$ dos níveis de treonina digestível sobre as composições de gordura e de proteína corporal das matrizes ao desmame. No entanto, os níveis de treonina influenciaram as mobilizações total $(\mathrm{P}<0,04)$ e percentual $(\mathrm{P}<0,07)$ de gordura corporal, que reduziram linearmente de acordo com o aumento do nível de treonina digestível da dieta (Figura 3).

Os níveis de treonina digestível não afetaram $(\mathrm{P}>0,10)$ as mobilizações total e percentual de proteína corporal das matrizes. Verificou-se variação de peso máxima de 7,28\% no nível de treonina $(0,64 \%)$ da dieta basal, resultando em perda média de 13,88 e 7,02\%, respectivamente, do total de gordura e proteína corporal. Essa mobilização é inferior à

Tabela 3 - Desempenho de fêmeas suínas em lactação alimentadas com dietas com diferentes níveis de treonina digestível Table 3 - Performance of lactating sows fed diets with different levels of digestible threonine

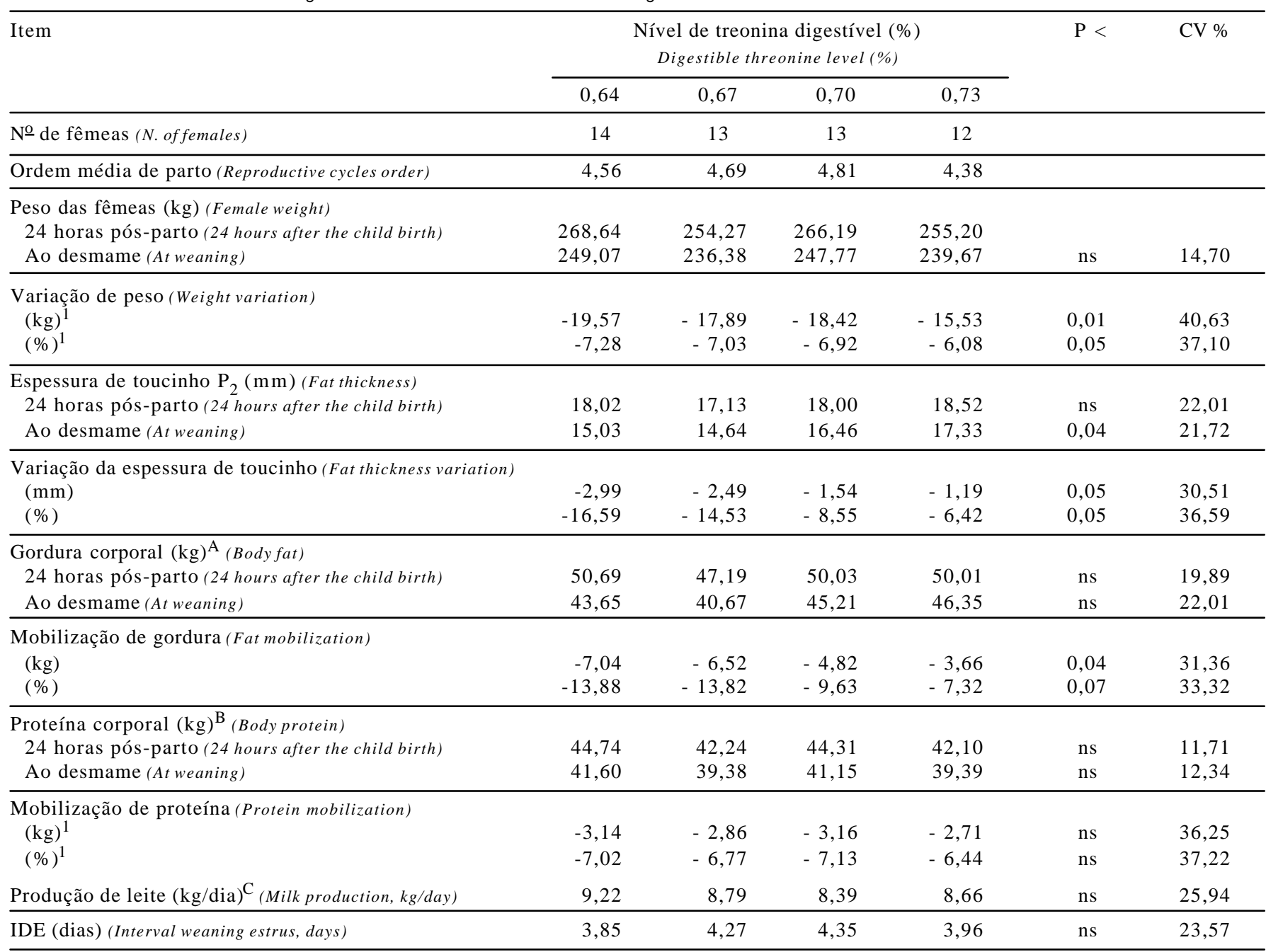

${ }^{1}$ Efeito linear (Linear effect); ns Efeito não-significativo (Not significant effect).

A Gordura corporal $(\mathrm{kg})$ (Body fat, $\mathrm{kg})=-11,58+\left[(0,1027 \times \mathrm{PC}, \mathrm{kg})+\left(1,904 \times \mathrm{ET} \mathrm{P} \mathrm{P}_{2} \mathrm{~mm}\right)\right](\mathrm{CVB}, 1994)$.

B Proteína corporal $(\mathrm{kg})$ (Body protein, $\mathrm{kg})=-2,3+[(0,19 \times \mathrm{PC}, \mathrm{kg})-(0,22 \times \mathrm{ET} \mathrm{P}, \mathrm{mm})]$ (Clowes et al. (2003).

C Produção de leite $(\mathrm{kg} / \mathrm{dia})=[(4,27 \times$ ganho de peso do leitão no período, $\mathrm{kg}) \times$ nº leitões $] / \mathrm{n}^{\circ}$ dias de lactação (Milk production, $\mathrm{kg} /$ day $=[(4,27 \times$ gain of weight of the pig in the period, $\mathrm{kg}) \times n^{\circ}$ pigs $/ / n^{\circ}$ days of lactation) (Ferreira et al., 1988). 


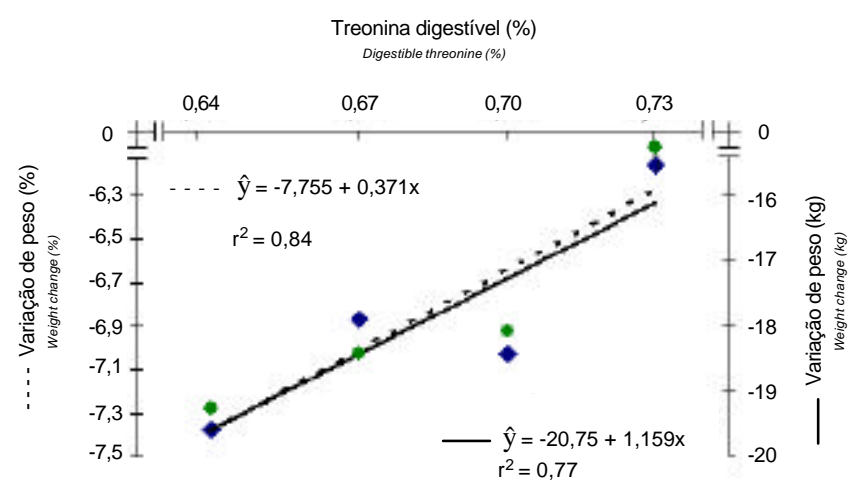

Figura 1 - Variações absoluta e percentual do peso em fêmeas suínas em lactação alimentadas com dietas com diferentes níveis de treonina digestível.

Figure 1 - Absolute and percent changes of weight in lactating sows fed diets with different levels of digestible threonine.

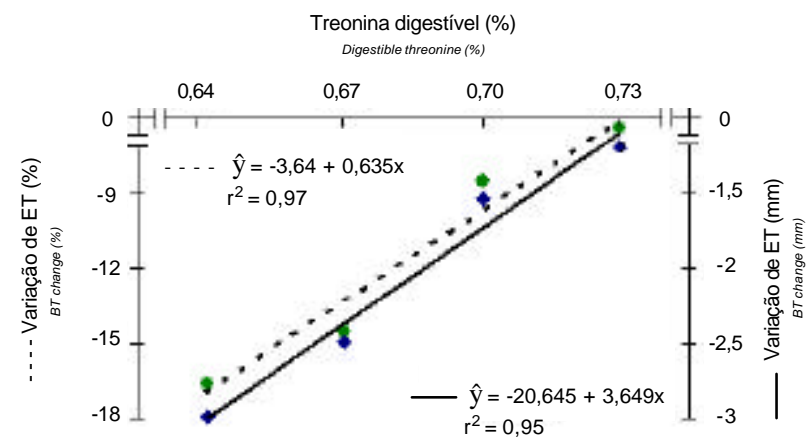

Figura 2 - Variações absoluta e percentual de espessura de toucinho em femeas suínas em lactação alimentadas com dietas contendo diferentes níveis de treonina digestível.

Figure 2 - Absolute and percent change of fat thickness of lactating sows fed diets with different levels of digestible threonine.

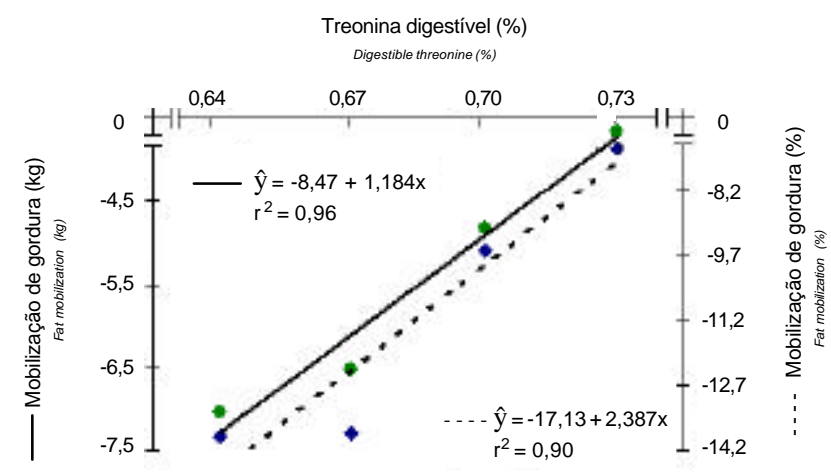

Figura 3 - Mobilizações absoluta e percentual de gordura corporal em femeas suínas em lactação alimentadas com dietas com diferentes níveis de treonina digestível.

Figure 3 - Absolute and percent mobilizations of corporal fat of lactating sows fed diets with different levels of digestible threonine. observada por Clowes et al. (2003), que relataram que porcas podem sofrer perdas de até $12 \%$ de sua massa protéica corporal durante a lactação sem, no entanto, afetar negativamente o crescimento dos leitões e da leitegada.

Não houve efeito $(\mathrm{P}>0,10)$ dos níveis de treonina na produção diária estimada de leite, cujos valores permaneceram entre 8,39 e 9,22 kg/dia. Esses valores podem ser considerados inferiores aos preconizados como ideais para animais de alto potencial genético, uma vez que as matrizes contemporâneas de alto potencial genético podem chegar a produção diária estimada superior a $10 \mathrm{~kg}$ de leite, considerando um período de lactação de 21 dias e uma conversão de $4 \mathrm{~g}$ de leite para cada g de ganho de peso da leitegada (Boyd et al., 2000). Contudo, a produção de leite estimada neste estudo pode ser considerada satisfatória, pois as temperaturas ambientais registradas durante o período experimental foram elevadas $\left(29,7^{\circ} \mathrm{C}\right)$. Além disso, os resultados de produção de leite obtidos estão acima dos valores de 6,18 e de 7,25 kg/dia, estimados, respectivamente, por Quiniou \& Noblet (1999) e Renaudeau et al. (2001) para fêmeas lactantes mantidas em condições de temperatura ambiente similar ao deste trabalho $\left(29^{\circ} \mathrm{C}\right)$.

Os níveis de treonina digestível não influenciaram ( $\mathrm{P}>0,10)$ o IDE; os valores médios variaram entre 3,85 e 4,35 dias e foram inferiores aos observados por Johnston et al. (1999), que avaliaram porcas lactantes mantidas em ambiente de alta temperatura $\left(29^{\circ} \mathrm{C}\right)$ e obtiveram IDE de 5,4 dias. IDE superior ao deste estudo também foi observado por Cooper et al. (2001), que avaliaram níveis de treonina digestível de 0,40 a $0,65 \%$ e obtiveram IDE médio de 5,7 dias. O valor máximo de IDE de 4,35 dias obtido neste estudo pode ser considerado um intervalo satisfatório, pois, segundo Sesti \& Sobestiansky (1998), o alvo de produtividade estabelecido para este parâmetro nas granjas de suínos é de cinco dias.

Não houve efeito $(\mathrm{P}>0,10)$ dos níveis de treonina digestível sobre os consumos diários de ração, de lisina e de energia digestível (Tabela 4). Uma vez que não houve variação no consumo diário de ração entre os níveis de treonina, constatou-se variação linear $(\mathrm{P}<0,01)$ do consumo diário de treonina digestível, que aumentou em razão do aumento de sua concentração nas dietas, conforme a equação: $\hat{Y}=-1,1103+46,033 X\left(r^{2}=0,99\right)$.

Os consumos diários de lisina digestível atenderam, em todos os níveis de treonina digestível, ao valor mínimo de $45 \mathrm{~g} /$ dia de lisina total, preconizado por Dourmad et al. (1998), e de $40 \mathrm{~g} /$ dia de lisina digestível, recomendado por Cota et al. (2003), para que as fêmeas apresentem perda mínima de peso corporal durante a lactação e não comprometam seu desempenho e de suas leitegadas. Além disso, 
Tabela 4 - Consumo e eficiência energética de fêmeas suínas em lactação alimentadas com dietas contendo diferentes níveis de treonina digestível

Table 4 - Intake and energy efficiency of lactating sows fed diets with different levels of digestible threonine

\begin{tabular}{|c|c|c|c|c|c|c|}
\hline \multirow[t]{2}{*}{ Item } & \multicolumn{4}{|c|}{$\begin{array}{c}\text { Nível de treonina digestível (\%) } \\
\text { Digestible threonine level }(\%)\end{array}$} & \multirow[t]{2}{*}{$\mathrm{P}<$} & \multirow[t]{2}{*}{$\mathrm{CV} \%$} \\
\hline & 0,64 & 0,67 & 0,70 & 0,73 & & \\
\hline Consumo ração (kg/dia) (Feed intake, kg/day) & 4,74 & 4,48 & 4,02 & 4,54 & & \\
\hline Consumo ração corrigido ( $\mathrm{kg} / \mathrm{dia})$ (Female feed intake corrected, $\mathrm{kg} /$ day) & 4,45 & 4,45 & 4,45 & 4,45 & & \\
\hline Cons. treonina digestível $(\mathrm{g} / \mathrm{dia})^{1}$ (Digestible threonine intake, g/day) & 30,33 & 29,99 & 28,15 & 33,13 & 0,001 & 0,71 \\
\hline Consumo lisina digestível (g/dia)(Digestible lysine intake, g/day) & 47,39 & 44,77 & 40,22 & 45,38 & ns & 0,08 \\
\hline Consumo energia digestível (Mcal/dia) (Digestible energy intake, Mcal/day) & 16,58 & 15,67 & 14,07 & 15,88 & ns & 0,06 \\
\hline Energia mantença (Mcal/dia) (Maintenance energy, Mcal/day) & 6,77 & 6,50 & 6,74 & 6,55 & ns & 8,39 \\
\hline Energia leite (Mcal/dia) (Milk energy, Mcal/day) & 10,29 & 9,71 & 9,15 & 9,77 & ns & 27,66 \\
\hline Balanço energético (Mcal/dia) (Energy balance, Mcal/day) & $-0,48$ & $-0,54$ & $-1,18$ & $-0,44$ & 0,001 & 45,65 \\
\hline Eficiência energética (Energy eficiency) & 1,87 & 1,89 & 1,89 & 1,83 & $\mathrm{~ns}$ & 23,52 \\
\hline
\end{tabular}

${ }^{1}$ Efeito linear (Linear effect).

ns Efeito não-significativo (Not significant effect).

com exceção da treonina digestível, cujos níveis e relações variaram, as relações dos demais aminoácidos essenciais com a lisina atenderam às relações mínimas preconizadas por Kim et al. (2001).

Não houve efeito $(\mathrm{P}>0,10)$ dos níveis de treonina digestível sobre as exigências de energia para a mantença e produção de leite. Contudo, constatou-se efeito $(\mathrm{P}<0,01)$ dos níveis de treonina sobre o balanço energético, que variou de forma quadrática melhorando até o nível de $0,697 \%$ de treonina digestível na dieta (Figura 4).

Ressalta-se que todas as dietas apresentaram balanço energético negativo, um resultado normal em fêmeas na fase de lactação. Uma possível explicação para a obtenção dessa resposta está relacionada à baixa ingestão de alimento atribuída às altas temperaturas ambientais e, conseqüentemente, à baixa ingestão de energia.

Não houve efeito $(\mathrm{P}>0,10)$ das dietas sobre o desempenho dos leitões e das leitegadas (Tabela 5). O ganho de peso das leitegadas obtido neste estudo foi semelhante ao de $2,11 \mathrm{~kg} / \mathrm{dia}$ de leitegadas de fêmeas mantidas em ambiente de conforto térmico $\left(17,7^{\circ} \mathrm{C}\right)$ e superior ao ganho de peso de $1,74 \mathrm{~kg} / \mathrm{dia}$ de leitegadas de fêmeas mantidas em estresse por calor $\left(27,1^{\circ} \mathrm{C}\right)$ observados em estudo realizado por Johnston et al. (1999). O ganho de peso das leitegadas obtido neste estudo também foi superior ao de 1,94 kg/dia observado por Quiniou \& Noblet (1999) em fêmeas mantidas em ambiente de alta temperatura $\left(29^{\circ} \mathrm{C}\right)$.

De acordo com os resultados obtidos, pode-se inferir que a exigência diária de treonina digestível para porcas lactantes visando minimizar a mobilização de tecidos corporais é de 32,49 g/dia. Este resultado é superior às exigências de 31 e de $28 \mathrm{~g} /$ dia de treonina total estimadas, respectivamente, para minimizar a perda de peso corporal (Westermeier et al., 1998) e maximizar a produção de leite (Paulicks et al.,

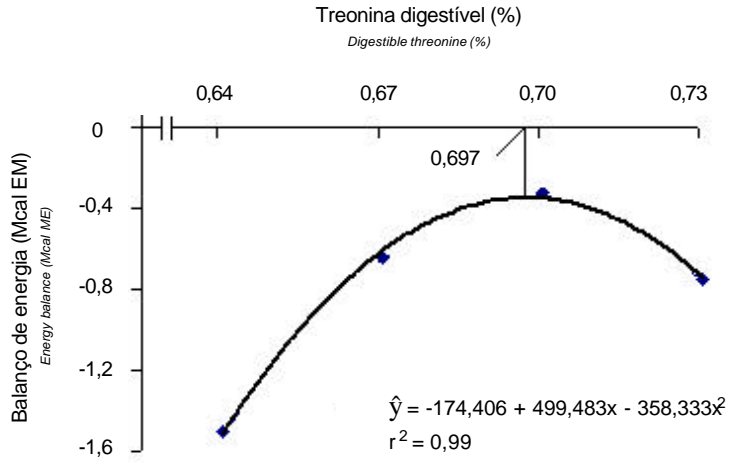

Figura 4 - Balanço energético em fêmeas suínas em lactação alimentadas com dietas com diferentes níveis de treonina digestível.

Figure 4 - Energy balance of lactating sows fed diets with different level of digestible threonine.

1998). Contudo, esse resultado foi similar à exigência de $36,7 \mathrm{~g} /$ dia de treonina total obtida por Reese et al. (2000) e às exigências de 37,40 e $38 \mathrm{~g} /$ dia para minimizar a mobilização de tecidos corporais, respectivamente, em fêmeas de $1 \stackrel{\mathrm{o}}{ }, 2 \underline{\mathrm{o}}$ e 3 o partos estimadas por Cooper et al. (2001).

Embora o aumento do nível de treonina digestível na dieta tenha proporcionado redução da mobilização de tecidos corporais durante a lactação, pode-se inferir que o nível de $0,64 \%$ de treonina digestível, correspondente à relação treonina digestível: lisina digestível de $64 \%$, foi satisfatório para manter o desempenho produtivo das porcas e de suas leitegadas. Esse resultado foi superior à recomendação de Rostagno et al. (2000), que propuseram relação de $61 \%$.

Relações superiores à obtida neste estudo também foram propostas por Kim \& Easter (2001), que estabeleceram relação de $62 \%$ (com mobilização tissular de $30 \%$ ), e por Kim et al. (2001), que propuseram relação de 69\%. Por outro lado, o resultado foi inferior às relações de 70 e $72 \%$ recomendadas, 
Tabela 5 - Desempenho de leitegadas de fêmeas suínas em lactação alimentadas com dietas com diferentes níveis de treonina digestível Table 5 - Performance of litters of lactating sows fed diets with different levels of digestible threonine

\begin{tabular}{|c|c|c|c|c|c|c|}
\hline \multirow[t]{2}{*}{ Item } & \multicolumn{4}{|c|}{$\begin{array}{c}\text { Nível de treonina digestível (\%) } \\
\text { Digestible threonine level (\%) }\end{array}$} & \multirow[t]{2}{*}{$\mathrm{P}<$} & \multirow[t]{2}{*}{$\mathrm{CV} \%$} \\
\hline & 0,64 & 0,67 & 0,70 & 0,73 & & \\
\hline \multicolumn{7}{|l|}{ № de leitões (N. of pigs) } \\
\hline 24 horas pós-parto (24 hours after-child birth) & 12,21 & 12,54 & 12,00 & 12,42 & $\mathrm{~ns}$ & 12,98 \\
\hline Ao desmame (At weaning) & 11,36 & 11,38 & 10,69 & 11,33 & $\mathrm{~ns}$ & 13,10 \\
\hline \multicolumn{7}{|l|}{ Leitões (kg) (Pigs) } \\
\hline 24 horas pós-parto (24 hours after child birth) & 1,63 & 1,50 & 1,58 & 1,37 & $\mathrm{~ns}$ & 23,09 \\
\hline Ao desmame (At weaning) & 5,62 & 5,30 & 5,44 & 5,13 & $\mathrm{~ns}$ & 14,62 \\
\hline Ganho de peso (g/dia) (Weight gain, g/day) & 201 & 188 & 192 & 191 & $\mathrm{~ns}$ & 19,76 \\
\hline \multicolumn{7}{|l|}{ Leitegada $(\mathrm{kg})($ Litter $)$} \\
\hline 24 horas pós-parto (24 hours after-child birth) & 19,86 & 18,85 & 19,04 & 17,04 & $\mathrm{~ns}$ & 24,65 \\
\hline Ao desmame (At weaning) & 64,00 & 61,08 & 58,15 & 58,42 & $\mathrm{~ns}$ & 20,69 \\
\hline Ganho de peso (kg/dia) (Weight gain, g/day) & 2,29 & 2,18 & 2,05 & 2,19 & $\mathrm{~ns}$ & 25,94 \\
\hline
\end{tabular}

ns Efeito não-significativo(Not significant effect).

respectivamente, pelo NRC (1998) e ARC (1981) e às relações de 65 a $71 \%$ estimadas pelo método fatorial por Dourmad et al. (1991).

Além disso, a exigência de treonina digestível de $0,64 \%$ obtida neste estudo foi superior ao nível de $0,50 \%$ estabelecido por Kansas (1994), ao nível de 0,58\% proposto pelo NRC (1998), aos níveis de 0,49 e 0,58\% recomendados, respectivamente, por Rostagno et al. $(2000,2005)$ e ao nível de $0,625 \%$ proposto por Kim et al. (2001).

\section{Conclusões}

Fêmeas suínas de alto potencial genético, sob condições de temperaturas ambientais elevadas, necessitamde $0,73 \%$ de treonina digestível, correspondente ao consumo diário de 32,5 g e à relação treonina digestível:lisina digestível de $73,0 \%$.

\section{Literatura Citada}

AGRICULTURE RESEARCH COUNCIL - ARC. The nutrient requirement of pigs. Slough: Commonwealth Agriculture Bureaux, 1981.307p

BLACK, J.L.; MULLAN, M.L.; LORSCHY, M.L. et al. Lactation in the sow during heat stress. Livestock Production Science, v.35, p.153-170, 1993.

BOYD, R.D.; TOUCHETTE, K.J.; CASTRO, G.C. et al. Recent advances in amino acid and energy nutrition of prolific sows: Review. Journal of Animal Science, v.13, p.1638, 2000.

BRAGANÇA, M.; MOUNIER, A.M.; PRUNIER, A. Does feed restriction mimic the effects of increased ambient temperature in lactating sows? Journal of Animal Science, v.76, p.20172024, 1998.

BUFFINGTON, D.E.; COLAZZO-AROCHO, A.; CANTON, G.H. et al. Black globe-humidity index (BGHI) as comfort equation for dairy cows. Transaction ASAE, v.24, p.711-714, 1981.
CLOWES, E.J.; AHERNE, F.X.; FOXCROFT, G.R. et al. Selective protein loss in lactating sows is associated with reduced litter growth and ovarian function. Journal of Animal Science, v. 81, p.753-764, 2003.

COOPER, D.R.; PATIENCE, J.F.; ZIJLSTRA, R.T. et al. Effect of nutrient intake in lactation on sow performance: Determining the threonine requirement of the high-producing lactating sow. Journal of Animal Science, v.79, p.23782387, 2001.

COTA, T.S.; DONZELE, J.L.; OLIVEIRA, R.F.M. et al. Níveis de lisina em ração de lactação para fêmeas suínas primíparas. Revista Brasileira de Zootecnia, v.32, n.1, p.115-122, 2003.

CENTRAL VEevoederbureau - CVB. Normen voor dragende zeugen (Requirements for pregnant sows). Lelystad: Central Veevoederbureau, 1994. p.51 (Documentation Report, 9).

DOURMAD, J.Y.; NOBLET, J.; ETIENNE, M. Effect of protein and lysine supply on performance, nitrogen balance, and body composition changes of sows during lactation. Journal of Animal Science, v.76, p.542-550, 1998.

DOURMAD, J.Y.; ETIENNE, M.; NOBLET, J. Contribution à l'etude des besoins en acides aminés delatruieenlactation. Journal Recherche Porcine, v.23, p.61-68, 1991.

FERREIRA, A.S.; COSTA, P.M.A.; PERREIRA, J.A.A. et al. Estimativas de produção de leite de porca. Revista Brasileira de Zootecnia, v.17, n.3, p.203-211, 1988.

JOHSNSTON, L.J.; ELLIS, M.; LIBAL, G.W. et al. Effect of room temperature and dietary amino acid concentration on performance of lactating sows. Journal of Animal Science, v.77, p.1638-1644, 1999.

KANSAS SWINE NUTRITION GUIDE. Cooperative extension service. Kansas: Kansas State University, 1994. 12p.

KIM, S.W.; BAKER, D.H.; EASTER, R.A. Dynamic ideal protein and limiting amino acids for lactating sows: the impact of amino acid mobilization. Journal of Animal Science, v.79, p.23562366, 2001

KIM, S.W.; EASTER, R.A. Nutrient mobilization form body tissues as influenced by litter size in lactating sows. Journal of Animal Science, v.79, p.2179-2186, 2001.

NATIONAL RESEARCH COUNCIL - NRC. Nutrient requirements of swine. 10.ed. Washington, D.C.: National Academic of Science, 1998. 189p.

PAULICKS, B.R.V.; WESTERMEIER, C.; KIRCHGESSNER, M. Milchmenge und Milchinhaltsstoffe bei Sauen in Abhangigkeit von der Threoninversorgung. 2. Mitteilung zumm Threoninbedarf 
laktierender Sauen. Journal of Animal Physiology Animal Nutrition, v.79, p.102-111. 1998.

QUINIOU, N.; NOBLET, J. Influence of high ambient temperatures on performance of multiparous lactating sows. Journal of Animal Science, v.77, p.2124-2134. 1999.

REESE, D.E.; THALER, R.C.; BRUMM, M.C. et al. [2000].Swine nutrition guide. University of Nebraska. Disponível em: <http://ianrwww.unl.edu/pubs/swine/ec273.htm.> Acesso em: 01/ 09/2004.

RENAUDEAU, D.; QUINIOU, N.; NOBLET, J. Effects of exposure to high ambient temperature and dietary protein level on performance of multiparous lactating sows. Journal of Animal Science, v.79, p.1240-1249, 2001.

RENAUDEAU, D.; NOBLET, J.; DOURMAD, J.Y. Effect of ambient temperature on mammary gland metabolism in lactating sows. Journal of Animal Science, v.81, p.217-231. 2003.

ROSTAGNO, H.S.; ALBINO, L.F.T.; DONZELE, J.L. et al. Composição de alimentos e exigências nutricionais. Tabelas brasileiras para aves e suínos. Viçosa, MG: Universidade Federal de Viçosa, 2000. 141p.

ROSTAGNO, H.S.; ALBINO, L.F.T.; DONZELE, J.L. et al. Composição de alimentos e exigências nutricionais. Tabelas brasileiras para aves e suínos. Viçosa, MG: Universidade Federal de Viçosa, 2005. 186p.

SAUBER, T.E.; STAHLY, T.S.; EWAN, R.C. et al. Interactive effects of sow genotype and dietary amino acid intake on lactational performance of sows nursing large litters. Journal of Animal Science, v.72 (suppl.2), p.66 (Abstr.), 1994.
STATISTICAL ANALYSIS SYSTEM - SAS. User's guide . version 6, 4.ed. Cary: 1996. 1686p.

SESTI, L.A.C.; SOBESTIANSKY, J. Alvos de produtividade. In: SOBESTIANSKY, J.; WENTZ, I.; SILVEIRA, P.R.S. et al. (Eds.) Suinocultura intensiva: produção, manejo e saúde do rebanho. Brasília: Embrapa - SPI; Concórdia: Embrapa-CNPSa, 1998. p.27-44.

TURCO, S.H.N.; FERREIRA, A.S.; BAÊTA, F.C. et al. Avaliação térmica ambiental de diferentes sistemas de acondicionamento em maternidades suinícolas. Revista Brasileira de Zootecnia, v.27, n.5, p.974-981. 1998

WESTERMEIER, C.; PAULICKS, B.R.V.; KIRCHGESSNER, M. Futteraufnahme und Lebendmasseentwicklung von Sauen und Ferkeln wahrend der Laktation in Abhangigkeit von der Threoninversorgung der Sauen. 1. Mitteilung zum Threoninbedarf laktierender Sauen. Journal of Animal Physiology Animal Nutrition, v.79, p.33-45, 1998.

WHITTEMORE, C.T.; ELSLEY, F.W.H. Practical pig nutrition. 2.ed. Edinburgh: Farming Press, 1979. 190p. 